\title{
CAPITAL SOCIAL, PRECARIZAÇÃO E UBERIZAÇÃO DO TRABALHO
}

SOCIAL CAPITAL, PRECARIOUSNESS AND UBERIZATION OF WORK

\author{
Ana Christina Tavares Martins ${ }^{1}$ \\ Maria Geralda de Miranda ${ }^{2}$
}

\begin{abstract}
Resumo: Neste rápido estudo serão examinadas as relações entre capital social, organização do trabalho, precarização, terceirização, economia compartilhada e uberização das relações com a formação de novas opções para o mercado e o trabalhador. Será analisada se a entrada das empresas ponto com e a atuação através de aplicativos (e-hailing) trazem realmente mais liberdade, autonomia e melhores ganhos para os trabalhadores individuais ou se o melhor lucro e as vantagens continuam na mão das empresas. Será verificado o quantum de capital social o trabalhador coloca ou não nesta "nova" forma de relação trabalhista, se ainda existem patrões ou não neste mercado virtual.
\end{abstract}

Palavras-chave: Uber. Uberização. Compartilhada.

Abstract: In this fast study the relations between social capital, organization of work, precariousness, outsourcing, sharing economy and the uberization of relations by the formation of new options for the market and for the worker are examined. Will be analyzed if the entrance of 'dot com' companies and the acting through the apps (ehailing) really bring more freedom, autonomy and better earnings for the individual workers or if the better profit and the advantages still in the hands of the companies. Will be verified the quantum of the social capital the worker put or not in this 'new' work relation form, if bosses still exist ou not in this virtual market.

Keywords: Uber. Uberization. Sharing.

\footnotetext{
${ }_{1}^{1}$ Mestranda do programa de Pós-Graduação em desenvolvimento Local da UNISUAM.

${ }^{2}$ Mestre em Literatura Comparada com ênfase nos estudos culturais pela Universidade Federal Fluminense (UFF) e Doutorado em Letras com ênfase em estudos pós-coloniais, também pela UFF. Fez pós-doutorado em Estudos de Literaturas Africanas de Língua Portuguesa pela UFRJ. É professora do Programa de Pós-Graduação em Desenvolvimento Local, do Centro Universitário Augusto Motta, UNISUAM, onde também e professora titular.
} 


\section{INTRODUÇÃO}

O presente artigo visa verificar como as empresas ponto com de economia compartilhada se beneficiam dos recursos do capital social, sem realizarem grandes investimentos, apropriando-se de benefícios das redes de relações e da confiança mútua. Organizadas em modelos, "uberizados", absorvem o potencial dos grupos e a base de mobilização individual para alterar regimes de trabalho, precarizar relações trabalhistas e criar formas não regulamentadas para aferir lucros expressivos sobre a força de grande número indivíduos. O estudo está dividido entre considerações sobre o capital social e as redes de relações com as diferentes formas de atuação dos laços fortes e fracos no sistema de uberização, em uma breve reflexão sobre a organização do trabalho do teylorismo, fordismo, toyotismos, a precarização do trabalho e as relações com o fenômeno da uberização. Finalmente, é abordada a entrada da economia compartilhada no mercado, o engajamento com as empresas ponto com, a forma de aproveitamento do capital social e das redes de relações pelo modelo de empresa uberizada e a posição melhorada ou não do trabalhador "independente" na relação com a nova organização do trabalho.

\section{CAPITAL SOCIAL NAS REDES DE RELAÇÕES}

As relações entre o homem e o trabalho, as formas de valoração de suas atividades na construção da sociedade mostram o status conquistado na sustentação na complexa teia social humana. São posições construídas pelas funções exercidas pelos indivíduos e pelas trocas que acontecem entre eles ao fazerem parte de diversificados grupos, que se entrelaçam em uma trama de informações e movimentos. Essa intrincada e dinâmica composição tem sido examinada por diversos autores a partir da ótica da economia, da antropologia, da sociologia etc. Dentre estes caminhos de pesquisa, uma forma de analisar estas ideias é o estudo do poder das redes de relações. No caso, a referência é feita ao esforço de compreender os efeitos dessas redes na construção da organização econômica e na dinâmica de atuação dos indivíduos dentro delas. Elementos que 
são dotados se suas capacidades, reunidos de forma legitimada, para somar e misturar suas aptidões e gerar novos poderes de produção.

O conceito de redes aqui referido apoia-se no que Marteleto e Silva expõem:

As redes são sistemas compostos por "nós" e conexões entre eles que, nas ciências sociais, são representados por sujeitos sociais (indivíduos, grupos, organizações etc.) conectados por algum tipo de relação. De forma genérica, pode-se estudar o sistema visando apenas entender como ele se comporta e como as conexões influenciam esse comportamento [...] (MARTELETO; SILVA, 2004, p. 41).

A análise das redes de relações é desenvolvida no âmbito da pesquisa de autores que se dedicam à elaboração e à exploração dos conceitos de capital social, como os que serão abordados no presente artigo, no caso, Pierre Bourdieu, James Coleman e Robert Putnam.

O conceito de capital social passa em primeiro lugar pelo sociólogo francês Pierre Bourdieu que o apresenta como:

[...] o conjunto dos recursos reais ou potenciais que estão ligados à posse de uma rede durável de relações mais ou menos institucionalizadas de interconhecimento e de inter-reconhecimento mútuos, ou, em outros termos, à vinculação a um grupo, como o conjunto de agentes que não somente são dotados de propriedades comuns (passíveis de serem percebidas pelo observador, pelos outros e por eles mesmos), mas também que são unidos por ligações permanentes e úteis (BOURDIEU, 1998, p. 67).

Uma questão importante a se destacar nos estudos de Bourdieu é o quantum (volume) de capital social um indivíduo pode apresentar dentro das suas redes de relação. O quantum, traduzido por volume, é de caráter individual, seria a quantidade efetiva que cada membro da rede é capaz de mobilizar em termos de recursos de capital econômico, cultural e simbólico. Para Bourdieu, o capital social são esses recursos empregados pelas pessoas que estão posicionadas dentro de um grupo, fomentando o progresso social por meio das trocas entre as experiências práticas e no ambiente que o grupo (estrutura) oferece. 
$\mathrm{Na}$ conceituação de capital social, descrita aqui por Bourdieu, as ligações entre os membros da rede são úteis, e fica patente na afirmação a necessidade da confiança e do uso estratégico dos recursos para que o sucesso seja alcançado. Confiança esta que é dinâmica, ou seja, vai se fortalecendo tanto pelos laços relacionais fortes como pelos laços fracos ${ }^{3}$, à medida que o grupo atua como rede e se enriquece a partir da contribuição individual que se torna realidade ativa dentro do grupo. Portanto, evoluir na rede é como um investimento estrategicamente feito na construção e na aproximação para ligações (laços) cada vez mais fortes e, por isso, mais ativos em capital econômico e humano. Desta forma, fica claro que Bourdieu constrói um conceito em que o capital social é a conquista de um grupo e, de certa forma, um ativo, que pode ser cobiçado e capitalizado por grupos de economia compartilhada, como é o caso do Uber ou mesmo de empresas de marketing multinível ${ }^{4}$.

Segundo o sociólogo americano James Coleman (1990, p. 304), capital social é indicado como o conjunto das relações sociais nas quais o indivíduo vai figurar como parte integrante, sendo que este conjunto e a dinâmica das relações colaboram para que os objetivos sejam atingidos.

Há uma relação de confiança mútua entre as pessoas pertencentes a um grupo, formalmente organizadas ou não, gerando uma interdependência, um processo em que um membro não conseguiria realizar uma atividade senão em conjunto ou em parceria com o outro.

Dentro dos diversos tipos de relações sociais que o autor (Coleman) insere no conceito de capital social, encontram-se relações de

\footnotetext{
${ }^{3} \mathrm{O}$ conceito de laço pode ser entendido a partir de Wellman: "Laços consistem em uma ou mais relações específicas, tais como proximidade, contato frequente, fluxos de informação, conflito ou suporte emocional. A interconexão destes laços canaliza recursos para localizações específicas na estrutura dos sistemas sociais. Os padrões destas relações - a estrutura da rede social - organizam os sistemas de troca, controle, dependência, cooperação e conflito" (WELLMAN, 2001 apud RECUERO, 2009, p. 3).

${ }^{4}$ [...] modelo de negócio do marketing multinivel - MMN que também é conhecido como marketing em rede, haja vista que o MMN é uma estratégia empresarial de distribuição de bens e serviços, onde a divulgação dos produtos se dá pela indicação "boca a boca" feita por divulgadores (Distribuidores) independentes. Por esse trabalho, tais divulgadores recebem bônus que seriam utilizados nas bilionárias campanhas de propaganda tradicional, ou seja, TV, rádio e internet. Além da indicação dos produtos, os divulgadores podem indicar outras pessoas para entrar em sua rede e, assim, construir uma organização de escoamento de produtos e serviços com possibilidades de ganhos ilimitados (CAPDEVILLE; SOUZA, 2014, p. 66).
} 
expectativas e obrigações entre indivíduos que trocam favores; a existência de normas, com suas sanções e prêmios aplicáveis pelos atores beneficiários sobre os subordinados à norma; as relações de autoridade, em que um indivíduo concorda em ceder a outro o direito sobre suas ações em troca de uma compensação (financeira ou de outra espécie, como status, honra, deferência etc.); obtenção de informações de baixo custo entre indivíduos, o que, neste caso, pode ser enquadrado como uma troca de favores, obediência a normas ou adequação a uma relação de autoridade (SILVA; SANTOS, 2009, p. 4).

Todas essas expectativas, normas e favores, estabelecidas no sistema de trocas e merecimentos, parecem ter se fixado como normalidade de relações no entendimento da sociedade e dos trabalhadores, porque parecem surgir como partes regulares e fidedignas das relações econômicas. No mercado de trabalho atual, no qual se misturam as funções exercidas pela mão de obra informal, pela terceirizada e as relações uberizadas, as avaliações, as premiações e as "estrelinhas" como garantia do cumprimento das normas e da permanência no grupo não são questionadas pelos participantes. Estes se inserem nas redes criadas em torno de aplicativos, rede sociais, esquemas de marketing multinível; disponibilizam suas redes de relações gratuitamente para que empresas ponto com as utilizem como plataforma de publicidade, propaganda, aferição de hábitos de consumo, padrões de comportamento e mailings altamente segmentados, focados etc. Mesmo as ditas "redes sociais", como, por exemplo, o Facebook ou o Youtube, também impõem suas normas, seus padrões de comportamento e premiações para quem deseja permanecer e sobressair no grupo.

A reflexão está, portanto, no fato de que tudo que é conduzido gratuitamente aos grupos, seja na forma das empresas ponto com de economia compartilhada, seja nas mídias ou nas redes sociais, é fruto de capital social. Ao se olhar do ponto de vista que envolve capital humano, confiança individual compartilhada, dinâmicas geradas pelos indivíduos (laços fortes e laços fracos) que desenvolvem as relações dentro dos ambientes virtuais ou de aplicativos tornando-os cada vez mais eficientes e fazendo com que poucos compartilhem do capital monetário de volume maior.

Ao se tratar de capital social, ainda se faz necessário mencionar o cientista político americano Robert Putnam. Em sua obra Comunidade e Democracia: a Experiência da Itália Moderna (2000), ele assim caracteriza capital social: 
[...] diz respeito a características da organização social, como confiança, normas e sistemas, que contribuam para aumentar a eficiência da sociedade, facilitando as ações coordenadas (p. 177).

[...] O capital social facita a cooperação espontânea (p. 177).

[...] Práticas de mútua assistência, como as associações de crédito rotativo, preservam também investimentos em capital social (p. 179).

Putnam também expressa as referências ao capital social como inter-relação da confiança, normas e cadeias de reciprocidade, sendo estas as expressões mais importantes de participação do indivíduo dentro do grupo. Estas referências são claramente açambarcadas pelas empresas ponto com de economia compartilhada ao transformarem todas essas referências de confiança em valores percebidos pelos clientes de cada negócio, referendando confiabilidade que é transformada segundo as normas de mercado em ativos monetários. Além do respaldo que conferem aos negócios destas empresas quando são transformados em valores a serem percebidos pelos clientes, também são eficientemente trabalhadas pelo marketing para se transformarem em diferenciais de mercado desejáveis e capazes de fidelizar os consumidores.

\section{A ORGANIZAÇÃO DO TRABALHO E A PRECARIZAÇÃO}

Neste mesmo cenário de evolução da organização social e econômica, avaliam-se em paralelo algumas visões sobre o desenvolvimento da organização do trabalho, como o teylorismo, o fordismo e o toyotismo e, mais recentemente, o movimento que vem sendo denominado de uberização. Essas análises estão contidas nos estudos sobre a precarização do trabalho, ou seja, o quanto o trabalhador vem perdendo em termos de direitos, segurança, operacionalização de novos postos e mercados de trabalho, e mesmo desvalorização de sua força de trabalho em função daquilo que Ihe é pago em função de seu tempo, know-how e capital humano.

A partir da revolução industrial, o homem não parou mais de procurar formas mais sistemáticas e gestões disciplinadoras capazes de aumentar a produção e, teoricamente, o lucro com a venda em massa dos produtos manufaturados. Nesse 
movimento histórico, os trabalhadores sempre foram compelidos a adotar modelos e fórmulas de organização do labor que fossem capazes de fazê-los trabalhar de forma a aumentar os lucros dos donos das indústrias e do capital. Na história desse movimento, que em essência se repete, a presença do lucro nas mãos de alguns evolui com a tecnologia e ganha outros contornos no cenário das empresas ponto com de economia compartilhada. Entretanto, o alvo continua o mesmo, a concentração de capital nas mãos de poucos através do movimento de muitos.

A trilogia clássica desta história passa pelo teylorismo, o fordismo e o toyotismo. O teylorismo ou administração científica, desenvolvido pelo engenheiro americano Frederick Winslow Taylor, apresentava como principal foco a organização racional do trabalho por meio de uma série de normas e paradigmas que deveriam ser implantados nas linhas de produção.

Taylor pretendia definir princípios científicos para a administração das empresas. Tinha por objetivo resolver os problemas que resultam das relações entre os patrões e os operários. Como consequência, modificam-se as relações humanas dentro da empresa: o bom operário não discute as ordens, nem as instruções, faz o que lhe mandam fazer (SECRETARIA NACIONAL DE FORMAÇÃO POLÍTICA DO PARTIDO COMUNISTA BRASILEIRO, 2016, p. 7).

Com o ponto central na administração, o teylorismo acabou por formatar a base de muitas ideias das relações humanas e do posicionamento entre patrões e empregados, que ainda hoje reverberam fundo no comportamento de ambos os lados. Mesmo na era da tecnologia e dos novos formatos da organização do trabalho, um certo pano de fundo ainda pode ser percebido. Por exemplo, em uma central de teleatendimento cabe ao "colaborador" ater-se ao script em tela ao falar com o cliente e evitar ao máximo transferir o caso ao supervisor, sob pena de perder pontuação em sua avaliação funcional.

O fordismo, criado por Henry Ford, veio para unir o sistema de administração humana do teylorismo com a ideia da linha de produção, ou seja, a organização das máquinas. Ford implantou a concepção de esteira rolante ou linha de montagem, onde as peças dos automóveis passavam ao alcance das mãos dos trabalhadores que tinham que realizar sua função no menor período de tempo possível. Um dos 
pontos mais interessantes do fordismo é que, com o aumento de produção dos automóveis, fez com que os próprios operários pudessem adquiri-los. Nesse momento o público interno se consolida como primeiro consumidor da empresa, o Ford T passa a ser objeto de desejo dos operários.

O fordismo teve seu ápice no período posterior à Segunda Guerra Mundial, nas décadas de 1950 e 1960, que ficaram conhecidas na história do capitalismo como "os anos dourados". A crise sofrida pelos Estados Unidos na década de 1970 foi considerada uma crise do próprio modelo, que apresentava queda da produtividade e das margens de lucros. A partir da década de 1980, esboçou-se nos países industrializados um novo padrão de desenvolvimento denominado pós-fordismo ou modelo flexível (toyotismo), baseado na tecnologia da informação (SECRETARIA NACIONAL DE FORMAÇÃO POLÍTICA DO PARTIDO COMUNISTA BRASILEIRO, 2016, p. 8).

Também conhecido como sistema just-in-time, o modelo de organização de produção toyotista surgiu no Japão após a Segunda Guerra Mundial, mas tomou força na década de 1970, como modelo japonês que vinha a calhar com a crise do capitalismo. Nas linhas de produção, a filosofia era a qualidade total e só se produzia o que era demandado, evitando o acúmulo de veículos em um espaço de estoque que os japoneses não possuíam. A automação flexível permitia a fabricação de numerosos modelos, de maior qualidade e preços competitivos, prontos para atenderem ao mercado globalizado.

Processo de multifuncionalização da mão de obra, uma vez que, por se basear na mecanização flexível e na produção para mercados muito segmentados, a mão de obra não podia ser especializada em funções únicas e restritas como a fordista. Para atingir esse objetivo, os japoneses investiram na educação e qualificação de seu povo, e o toyotismo, em lugar de avançar na tradicional divisão do trabalho, seguiu também um caminho inverso, incentivando uma atuação voltada para o enriquecimento do processo de trabalho (SECRETARIA NACIONAL DE FORMAÇÃO POLÍTICA DO PARTIDO COMUNISTA BRASILEIRO, 2016, p. 9).

Por outro lado, o desenvolvimento da tecnologia e a necessidade de mão de obra mais qualificada reduziam a necessidade de trabalhadores necessários às indústrias. O desemprego em função da alta tecnologia se tornou tendência na 
organização do trabalho. Estavam em curso mais mudanças estruturais nos processos do capitalismo. Os novos cenários para combinação de flexibilização das relações de trabalho, economia globalizada e novas tecnologias surgindo a cada momento passaram a compor a nova ordem mundial. A palavra flexível se tornou o termo da moda para abordar o assunto empreendedorismo, dando ares de inovação e ousadia àqueles que se moldam e se encaixam nas regras do jogo deste "novo" capitalismo.

Segundo David Harvey, a incerteza que invade o novo panorama do capitalismo e as relações no mercado de trabalho tomou conta do aspecto social e econômico, abrindo espaço para uma série de novos arranjos e experiências. As mudanças políticas e as constantes oscilações da economia foram acomodando como saída construtiva na compreensão de mundo a ideia da acumulação flexível.

\begin{abstract}
A acumulação flexível envolve rápidas mudanças dos padrões de desenvolvimento desigual, tanto entre setores como entre regiões geográficas, criando, por exemplo, um vasto movimento no emprego no chamado "setor de serviços", bem como conjuntos industriais em regiões completamente novas [...] - os horizontes temporais da tomada de decisões privada e pública se estreitam, enquanto a comunicação [...] e a queda nos custos de transporte possibilitam cada vez mais a difusão imediata das decisões num espaço cada vez mais amplo e variegado. Esses poderes aumentados de flexibilidade e mobilidade permitem que os empregadores exerçam pressões mais fortes de controle do trabalho [...] (HARVEY, 1992, p. 131).
\end{abstract}

Desta forma, "flexibilidade" e "flexibilização" se tornam o novo caminho para nortear composições de economia compartilhada, expressões de inovação, e toda a campanha é feita a respeito da iniciativa empreendedora, como a salvação da economia e a solução para a aplicação de recursos de muitos trabalhadores que perderam seu emprego e sua capacidade de empregabilidade no mercado formal. Como bem observou Harvey, o setor de serviços é especialmente suscetível e atraente tanto para as empresas de economia compartilhada do setor ponto com como para os portadores de capital social (e algum capital financeiro), que passam a se reunir em redes sociais para estabelecer laços e vasculhar oportunidades.

Nesse panorama contínuo de precarização do trabalho, se mantêm como agentes influenciadores a sucessão das novas formas de trabalho a partir do 
processo de mudanças, na realidade, contínuas na estrutura do capitalismo; o processo de desconstrução salarial; a gradual perda de direitos trabalhistas; a globalização como fator de regularização da força de trabalho como mercadoria; a desregulamentação da jornada de trabalho e a instauração de novos modos da remuneração flexível. Este é o novo capitalismo flexível vigente, com suas inovadoras, e cada vez mais dinâmicas, modalidades de contratação salarial, em que se incluiria o fenômeno da uberização como mais uma modalidade de precarização da força de trabalho.

\section{ECONOMIA COMPARTILHADA E UBERIZAÇÃO}

Junte uma rede de pessoas interessadas em um mesmo objetivo, uma tecnologia para colocá-las em contato e, finalmente, o ingrediente principal, a confiança. Essa confiança pode vir da subjetividade que surge no entendimento de que pessoas com um interesse comum, organizadas por uma plataforma virtual que crie, monitore e organize dados, pode garantir que estranhos sejam menos estranhos. Essa forma de organização faz com que o pensamento se volte para a questão dos laços sociais fortes e fracos, e como o capital social dos sujeitos em rede pode se espalhar ou se multiplicar dando força e forma a essa confiança que vai impulsionar a economia colaborativa e as empresas ponto com que surgem sobre essa base.

Está formado neste ponto o ambiente favorável para que o indivíduo participante da rede com uma expressiva quantidade de laços fracos (muitos contatos) tenha condições para uma remuneração dentro do esquema de funcionamento das empresas ponto com de economia compartilhada. Está também organizada a estrutura para que os donos do capital das empresas que gerenciam a rede e fomentam a confiança (que se torna um elemento com valor de ativo financeiro) tenham um ganho extremamente vantajoso administrando o capital social. Este advém da rede de indivíduos e seus laços fracos, que com 0 funcionamento do negócio se multiplicam e fortalecem ainda mais o bem como valor, que é a confiabilidade. 
Granovetter (1973, p. 1361) coloca que uma das forças atuantes nos laços passa pela intensidade emocional e os serviços recíprocos trocados por membros da rede. Ele destaca o papel dos laços fracos na formação e na consolidação do tipo de relação de profundidade menor de conhecimento entre os "amigos" de uma rede social, como o Facebook.

Vimos que laços sociais são combinações de relações sociais, que, por sua vez, são compostas de interações. Laços são, portanto, conexões construídas durante as trocas sociais entre os atores de uma determinada rede. Laços possuem, portanto, algum nível de reciprocidade em sua constituição (RECUERO, 2009, p. 4).

Entende-se a partir daí que os laços fracos que se multiplicam em um volume muito maior nas redes sociais podem servir de esteio para construir a referida conexão de confiança e promover o encontro de milhares de pessoas capazes de dar suporte a uma empresa ponto com de economia compartilhada, como é o caso do Uber e do Airbnb. Na introdução do livro O que é meu é seu: como o consumo colaborativo vai mudar do mundo, de Raquel Botsman e Roo Rogers (2001, p. 10), os autores destacam que foram estas algumas das questões sobre as quais os fundadores do Airbnb refletiram para a decisão de formar o negócio - a prestação de serviços e a formação de pares, em que a confiança pode ser construída como elemento de sucesso da prestação de serviço e do negócio.

No caso do Brasil, a atuação exclusiva no mercado do serviço de táxis, a insatisfação dos clientes com os valores cobrados e a qualidade oferecida abriram espaço para a receptividade positiva na chegada da empresa norte-america de transporte privado de passageiros Uber, em maio de 2014, como registra o site "Seja parceiro Uber". O modelo é conhecido como e-hailing, procedimento de se solicitar um táxi através de um dispositivo eletrônico, normalmente um celular ou smartphone. A empresa foi uma das pioneiras no uso do conceito e-hailing, começou a operar em 2009, em São Francisco (Califórnia) a partir da ideia dos empresários Garrett Camp e Travis Kalanick de oferecerem uma espécie de táxi de luxo, como carros de modelos superiores, por meio de um aplicativo tanto para Android como para iPhone. Do ponto de vista da recepção pela população do novo 
serviço, Botsman e Rogers (2011, p. 19) ponderam: "Consumo colaborativo não tem nada a ver com compartilhamento forçado e educado. Pelo contrário, ele coloca em vigor um sistema em que as pessoas dividem recursos sem perder liberdades pessoais apreciadas e sem sacrificar seu estilo de vida".

Além da aceitação pelos consumidores, há que se levantar também a ideia dos que abordam o Uber ou modelo uberizado pelo lado da inovação. A referência no caso é àquilo que vem sendo tratado como inovação desruptiva, conceito apresentado por Clayton M. Christensen, professor da Harvard Business School ${ }^{5}$, que classifica a capacidade de um produto ou serviço de ascender no mercado e conquistar um espaço novo e dominá-lo. O conceito não propõe a evolução ou a revolução de um determinado produto ou serviço, mas uma inovação tecnológica capaz de promover o acesso de muitos ao novo.

A conjunção de todos esses conceitos com o conceito e-hailing, a inovação desruptiva, o desejo da sociedade por formas de relações comerciais colaborativas, nas quais o foco está no acesso a bens e serviços, ao invés da posse destes, e a predisposição do mercado por conta da insatisfação com um serviço de modelo monopolizado não mudam a constatação de que os trabalhadores que ingressam nesses tipos de organização disponibilizam seu capital social (principalmente na forma dos laços fracos) para plataformas virtuais ganharem um montante de dinheiro que não passa nem perto do que é percebido como lucro ou benefícios pessoais por esses trabalhadores. Isto significa dizer que o Uber acessa recursos já existentes do capital social e das redes de relação dos trabalhadores para promover seu impacto no mercado como inovação desruptiva. O que pode ser avaliado hoje em matéria do portal de notícias G1 é que o Uber tem um valor de mercado de US $\$ 62,5$ bilhões ${ }^{6}$, sem que isso se reflita em qualquer garantia ou direto trabalhista para aqueles que emprestam sem tempo, sua força de trabalho e seus veículos para a referida ponto com.

É possível ponderar:

\footnotetext{
${ }^{5}$ Disponível em: < http://www.claytonchristensen.com/key-concepts/>. Acesso em: 4 dez. 2016.

${ }^{6}$ Disponível em: < http://g1.globo.com/tecnologia/noticia/2016/06/uber-recebe-investimento-de-us-35bilhoes-da-arabia-saudita.html>. Acesso em: 4 dez. 2016.
} 
Essas empresas de táxis criaram uma subcategoria de taxistas que são os auxiliares, que trabalham no regime de diárias. Estes saem para trabalhar já devendo um valor alto ao dono da licença, que são também donos dos carros. Estes trabalhadores, denominados taxistas auxiliares, são explorados e precisam trabalhar muito, porque, além de ganharem para a manutenção de suas vidas e dos carros, precisão pagar aos patrões, que não se consideram patrões, e se sentem, portanto, isentos das responsabilidades trabalhistas em relação aos empregados, que trabalham, às vezes, 18 horas sem intervalo. [...] A polêmica em torno do Uber por parte dos taxistas, na verdade, não é empreendida pelos taxistas auxiliares, os mais radicalmente preocupados com o rumo dos negócios são os donos de empresas de táxis, estas sim ameaçadas pela inovação e concorrência do Uber (REIS; AVELAR; MIRANDA, 2016, p. 179-180).

No entanto, nada do que é disposto pelos autores no trecho reproduzido acima vai contra a avaliação feita sobre o modelo uberizado. Nos dois casos existe a precarização do trabalho, que acontece por vias diferentes. No caso do Uber, a utilização do capital social (ativos econômicos, culturais e simbólicos) via rede de relações com seus laços fracos, facilmente propagados e referendados pelas “amizades" nas mídias, promovem a diferença de abordagem por meios virtuais. Mas sem a isenção de responsabilidades daqueles que são patrões, assim se considerando ou não.

O economista Marcio Pochmann destaca como efeito da uberização uma mudança na relação entre os trabalhadores. Ele aponta para um crescente individualismo que aumenta a competitividade e vem travestido no discurso encantador do empreendedorismo, que em tempos de recessão ganha ainda mais força.

Com a uberização, há uma competição ainda maior entre os trabalhadores e quem estabelece ou avalia a sua continuidade nesse tipo de trabalho é o cliente, o comprador. Ao invés da união buscando o acordo coletivo, o trabalhador está orientado para o acordo individual, a competição com seus pares. Obviamente isso torna ainda mais fracos os trabalhadores diante daqueles que os contratam. Esse rebaixamento não é só econômico, mas também moral e ético. 
[...] O que nós passamos a ter na verdade é uma transição para esta ideia não mais de trabalhador, mas de empreendedor. Você pode ganhar como trabalhador, mas tem os anseios de classe média consumista. É uma disputa ideológica. Se você não admite ser trabalhador, as lutas dos trabalhadores vão se perdendo. Você é da classe média e é o seu esforço que vai fazer com que você alcance os resultados. A propaganda ideológica mostra que alguns de fato ficarão em situação melhor, mas serão uma exceção num conjunto grande, legitimando um grau de desigualdade ainda mais intenso (POCHMANN, 2016).

Sobre a questão dos ganhos reais dos trabalhadores uberizados no Brasil, ainda é muito recente para que estudos sejam expostos com precisão numérica. Mas no Reino Unido, onde o fenômeno já é mais antigo, o The Guardian apontou em reportagem que o chamado self-employment, ou autoemprego, cresceu $45 \%$ desde 2002, mas que esses trabalhadores ganham hoje, em média, menos do que em 1995.

If that was the dream, welcome to the nightmare. Self-employed earn less than in 2001 - and will be hit by welfare cuts.

Self-employment is rising in many economies. In the UK it has grown by a staggering $45 \%$ since 2002 . But here's the catch. The chances of becoming the next uber-wealthy Richard Branson are fairly slim. A recent study has found that the average self-employed contractor is now paid less than in 1995. So how did the dream of becoming our own boss turn into such a bad deal for all the construction workers, IT consultants, nurses and courier drivers who believed that being selfemployed would be a path to economic freedom? In short, neoliberalism (FLEMING, 2016). ${ }^{7}$

\section{CONSIDERAÇÕES FINAIS}

\footnotetext{
7 "Se esse era o sonho, bem-vindo ao pesadelo. Os trabalhadores independentes ganham menos do que em 2001 - e serão atingidos por cortes nos benefícios sociais. O autoemprego tem aumentado em muitas economias. No Reino Unido tem crescido em uma proporção de $45 \%$ desde 2002. Mas aqui está a armadilha. As chances de se tornar o próximo Uber milionário Richard Branson são bastante pequenas. Um estudo recente descobriu que o empregado médio autônomo recebe hoje menos do que em 1995. Então, como o sonho de se tornar o próprio chefe virou um negócio tão ruim para todos os trabalhadores da construção, consultores de $\mathrm{Tl}$, enfermeiros e entregadores que acreditavam que ser autônomo seria um caminho para a liberdade econômica? Em resumo, o neoliberalismo" (tradução nossa).
} 
Ao se estabelecerem relações entre capital social, precarização do trabalho e uberização, o cenário encontrado não difere em essência da presença de um elemento terceirizador. Este vai organizar e canalizar a força de trabalho por meio do capital social (ativos econômicos, culturais e simbólicos); fazer o melhor uso para si das redes relacionais, seja por meios virtuais, e-hailing, economia compartilhada ou modus operandi tradicionais, procurando sempre a melhor maneira de administrar os elementos que irão se converter em ativos monetários cada vez mais lucrativos para esses agentes terceirizadores, que podem ao longo da mudança da economia, dos mercados, da política e da tecnologia adquirir variadas interfaces. Mas para o chamado self-employment, as relações continuam a se reproduzir, isentas inúmeras vezes de contratos de prestação de serviços amparados por garantias trabalhistas; ainda por cima, a realidade de ficar com a menor fatia do lucro não se tem alterado. O trabalhador entra com a sua força de trabalho, o seu capital (carro), o conhecimento de direção e circulação nas cidades, a capacidade de atendimento ao público, o combustível, além dos riscos inerentes ao trabalho. A empresa, por sua vez, entra com o marketing, a estrutura de rede, e a marca que confere uma aura de segurança e confiabilidade para o cliente.

\section{REFERÊNCIAS}

BOTSMAN, R.; ROGERS, R. O que é meu é seu: como o consumo colaborativo vai mudar o nosso mundo. Porto Alegre: Bookman, 2011.

BOURDIEU, Pierre. O Capital Social - Notas Provisórias. In: NOGUEIRA, Maria Alice; CATANI, Afrânio (Org.). Escritos de educação. Petrópolis: Vozes, 1998 [1980]. p. 67.

CAPDEVILLE, Adrienne; SOUZA, José Marques de. Marketing Multinível. Periódico Científico Negócios em Projeção, Brasília, DF, v. 5, n. 2, p. 66-78, 2014.

CHRISTENSEN, Clayton. Disruptive innovation. Disponível em: <http://www. claytonchristensen.com/key-concepts/>. Acesso em: 4 dez. 2016.

COLEMAN, James Samuel. Foundations of social theory. Cambridge, MA: Harvard University Press, 1990. p. 304.

FLEMING, Peter. Self-employment used to be the dream. Now it's a nightmare, The Guardian, 2016. Disponível em: <https://www.theguardian.com/ 
commentisfree/2016/ oct/19/self-employment-dream-governments-gig-economy>. Acesso em: 4 dez. 2016.

GRANOVETTER, M. The Strength of Weak Ties. The American Journal of Sociology, v. 78, n. 6, p. 1360-1380, 1973.

HARVEY, David. Condição pós-moderna - Uma pesquisa sobre as origens da mudança cultural. São Paulo: Edições Loyola, 1992.

MARTELETO, Regina; SILVA, Antonio Braz de Oliveira e. Redes e capital social: o enfoque da informação para o desenvolvimento local. Revista Ciência da Informação, Brasília, DF, v. 33, n. 3, p. 41-49, set./dez. 2004. Disponível em: <http://www.scielo.br/pdf/ci/v33n3/a06v33n3.pdf>. Acesso em: 20 nov. 2016.

POCHMANN, Marcio. A uberização leva à intensificação do trabalho e da competição entre os trabalhadores, Diário Liberdade, 2016. Disponível em: https://gz.diarioliberdade.org/artigos-em-destaque/item/90878-marcio-pochmann-auberizacao-leva-a-intensificacao-do-trabalho-e-da-competicao-entre-ostrabalhadores. html. Acesso em: 4 dez. 2016.

PUTNAM, Robert D. Comunidade e democracia: a experiência da Itália moderna. Rio de Janeiro: Editora FGV, 2000.

RECUERO, Raquel. Mapeando Redes Sociais na Internet através da Conversação Mediada pelo Computador. In: HETKOWSKI, Tania Maria; NASCIMENTO, Antonio Dias (orgs.). Educação e Contemporaneidade: pesquisas científicas e tecnológicas. Salvador: EDUFBA, 2009. p. 251-274.

REIS, Friede; AVELAR, Kátia; MIRANDA, Geralda de. "O liberalismo, a inovação e o UBER". In Direito, pesquisa e inovação: Estudos em homenagem ao professor Maurício Jorge Pereira da Mota. Juiz de Fora, MG: Editar Editora Associada Ltda, 2016.

SEJA PARCEIRO DO UBER. Seja parceiro do Uber. Disponível em: <Uberhttp://sejaparceirouber.com.br/uber-conheca-a-empresa/>. Acesso em: 4 dez. 2016.

SILVA, Afrânio de Oliveira; SANTOS, Caroline. Capital social, capital humano e educação: o ensino da sociologia e a construção da cidadania. Perspectiva Sociológica, Rio de Janeiro, n. 2, 2009. Disponível em: <http://www.cp2.g12.br/ojs/index. php/PS/article/view/426/360>. Acesso em: 20 nov. 2016.

SECRETARIA NACIONAL DE FORMAÇÃO POLÍTICA DO PARTIDO COMUNISTA BRASILEIRO. Modos de Produção. Disponível em: <http://www.pcb.org.br/portal/docs/modosdeproducao.pdf>. Acesso em: 21 nov. 2016. 